\title{
INDIRECT COSTS IN PATIENTS WITH CORONARY ARTERY DISEASE AND MENTAL DISORDERS: A SYSTEMATIC REVIEW AND META-ANALYSIS
}

\author{
ANNE HASCHKE, NICO HUTTER, and HARALD BAUMEISTER \\ University of Freiburg, Germany \\ Institute of Psychology, Department of Rehabilitation Psychology and Psychotherapy
}

\begin{abstract}
The aim of the present study was to systematically review the association of comorbid mental disorders with indirect health care costs in patients with coronary artery disease (CAD). A comprehensive database search was conducted for studies investigating persons with CAD and comorbid mental disorders (Medline, EMBASE, PsycINFO, Psyndex, EconLit, IBSS). All studies were included, which allowed for a comparison of indirect health care costs between CAD patients with comorbid mental disorders and CAD patients without mental disorders. The literature search revealed 4962 potentially relevant studies, out of which 13 primary studies met the inclusion criteria. Depression was investigated most often $(\mathrm{N}=10)$, followed by anxiety disorders $(\mathrm{N}=3)$ and any mental disorder not further specified $(\mathrm{N}=3)$. All studies focused on return to work as indirect cost outcome. CAD patients with depression showed diminished odds for return to work, compared to $\mathrm{CAD}$ patients without depression $(\mathrm{OR}=0.37 ; 95 \% \mathrm{CI}: 0.27-0.51)$. The findings for comorbid anxiety and any mental disorder were inconsistent. Indirect health care costs were exclusively assessed by a patient self-report $(\mathrm{N}=13)$. There is strong evidence for diminished odds of return to work in CAD patients with comorbid depression, highlighting the need for integrated CAD and depression care. With regard to other comorbid mental disorders, however, the evidence is sparse and inconclusive.
\end{abstract}

\section{Key words:}

Coronary Artery Disease, Mental disorder, Comorbidity, Indirect health care costs, Systematic review

\section{INTRODUCTION}

Coronary artery disease $(\mathrm{CAD})$ poses a great economic burden to the health care system, compared to other chronic diseases [1]. Thereby, indirect health care costs are the second largest part of the overall health care costs with a total of $€ 10.7$ billion in the year 2006 in the EU [2]. Indirect costs are defined as potentially lost income due to the loss of productivity or sick leave days of the employee. They arise in three domains [3]:

- work absence,
- reduced productivity at paid work,

- unpaid production (reduced possibilities of performing usual activities at home).

In economic studies, indirect costs are usually conceptualized according to the human capital method or the friction cost method [4]. The human capital method measures indirect costs as the loss in productivity due to sickness of the employee. The friction cost method estimates the amount of production lost, as long as the initial production level is restored (e.g. by replacing the

This research project was funded by the Landesstiftung Baden-Württemberg. Received: February 6, 2012. Accepted: May 23, 2012.

Address reprint request to A. Haschke, Institute of Psychology, Department of Rehabilitation Psychology and Psychotherapy, University of Freiburg, Engelbergerstr. 41, D-79085 Freiburg, Germany (e-mail: anne.haschke@psychologie.uni-freiburg.de). 
employee). As a consequence, the friction cost method will result in lower cost estimates than the human capital method [4]. In public health research, indirect costs are most often operationalized as time till return to work or productivity loss of patients according to the human capital method.

Patients with $\mathrm{CAD}$ are at increased risk of developing mental disorders (OR $=1.9-2.7)$ [5]. These comorbid mental disorders have frequently been shown to impair health outcomes in CAD patients such as increased mortality [6] and diminished quality of life [7,8]. Comorbid mental disorders are also hypothesized to further increase indirect health care costs in $\mathrm{CAD}$ patients [9-11]. However, data regarding indirect health care costs in $\mathrm{CAD}$ patients with comorbid mental disorders are inconsistent $[12,13]$ and there might be a ceiling effect given the immense indirect costs in CAD patients.

To answer the question of whether indirect health care costs are increased in patients with CAD and mental disorders, the present study aims to systematically summarize and evaluate the association between comorbid mental disorders and indirect health care costs in CAD patients. The following research questions will be addressed:

1. To what extent are comorbid mental disorders in patients with $\mathrm{CAD}$ associated with increased indirect health care costs in comparison to patients without mental comorbidity?

2. Are there differences in this association with regard to specific comorbid mental disorders?

\section{MATERIALS AND METHODS}

Data collection for this systematic review was part of a larger systematic review on the quality of life and health care costs in somatically ill patients with comorbid mental disorders $[7,14,15]$. Health care costs were subdivided into direct and indirect costs. Indirect costs referred to the loss of working hours due to absence from the workplace, delayed return to work and impaired productivity $[4,16,17]$. The present review focuses on indirect costs in CAD patients with comorbid mental disorders compared to CAD patients without mental comorbidity.

\section{Inclusion criteria}

Studies investigating adult patients $(\geq 18)$ with $\mathrm{CAD}$ (ICD-10: I20-I25) in outpatient or inpatient settings as well as community samples were included. The inclusion of primary studies was not further limited to specific clinical subgroups in order to increase the generalizability of the results of the review.

The studies that were included allowed for the categorization of mental disorders or psychological burden corresponding to the following diagnostic categories:

1. Mental and behavioral disorders due to the use of alcohol (ICD-10: F10; DSM-IV: 303.xx, 291.xx).

2. Mood disorders (ICD-10: F30-F39; DSM-IV: 292.xx, 296.xx; 300.4, 301.13, 311).

3. Anxiety disorders (ICD-10: F40-F43; DSM-IV: 300.0x, 300.2x, 308.3, 309.81).

4. Somatoform disorders (ICD-10: F45; DSM-IV: 300.7, 300.81).

5. Eating disorders (ICD-10: F50; DSM-IV:307.1,307.5x).

6. Disorders of adult personality and behavior (ICD-10: F60; DSM-IV: 301.x).

7. Any mental disorder (i.e. assessment of psychiatric symptoms in general).

In order to be included, primary studies had to allow for a two group comparison regarding indirect costs between a group with one of the mentioned mental disorders and a group without the respective mental disorder.

Primary studies were included if they assessed any indirect cost outcome, either monetary or by cost outcomes like the productivity loss or return to work rates. 


\section{Search strategy}

The database search was conducted in the databases Medline, EMBASE, PsycINFO, Psyndex, EconLit and IBSS for articles published until 8 June 2010 using the search structure 'coronary artery disease' and 'mental disorders' and 'health care costs / health care utilization'. The comprehensive search strategy for Medline can be requested from the first author.

In a preliminary sensitive selection process, one reviewer (N.H.) screened titles and abstracts of English- or
German-language articles relating to direct or indirect health care costs studies in CAD $(\mathrm{N}=4962)$ (Figure 1). Then, two reviewers (N.H., A.H.) independently selected relevant studies for inclusion by examining the remaining titles, abstracts or full papers $(\mathrm{N}=1203)$. In the case of disagreement, a third reviewer (H.B.) was asked to review the article, and disagreements were solved by a consensus discussion. Further potentially relevant studies were retrieved by examining the reference lists of the included studies $(\mathrm{N}=71)$ and through the identification of the published

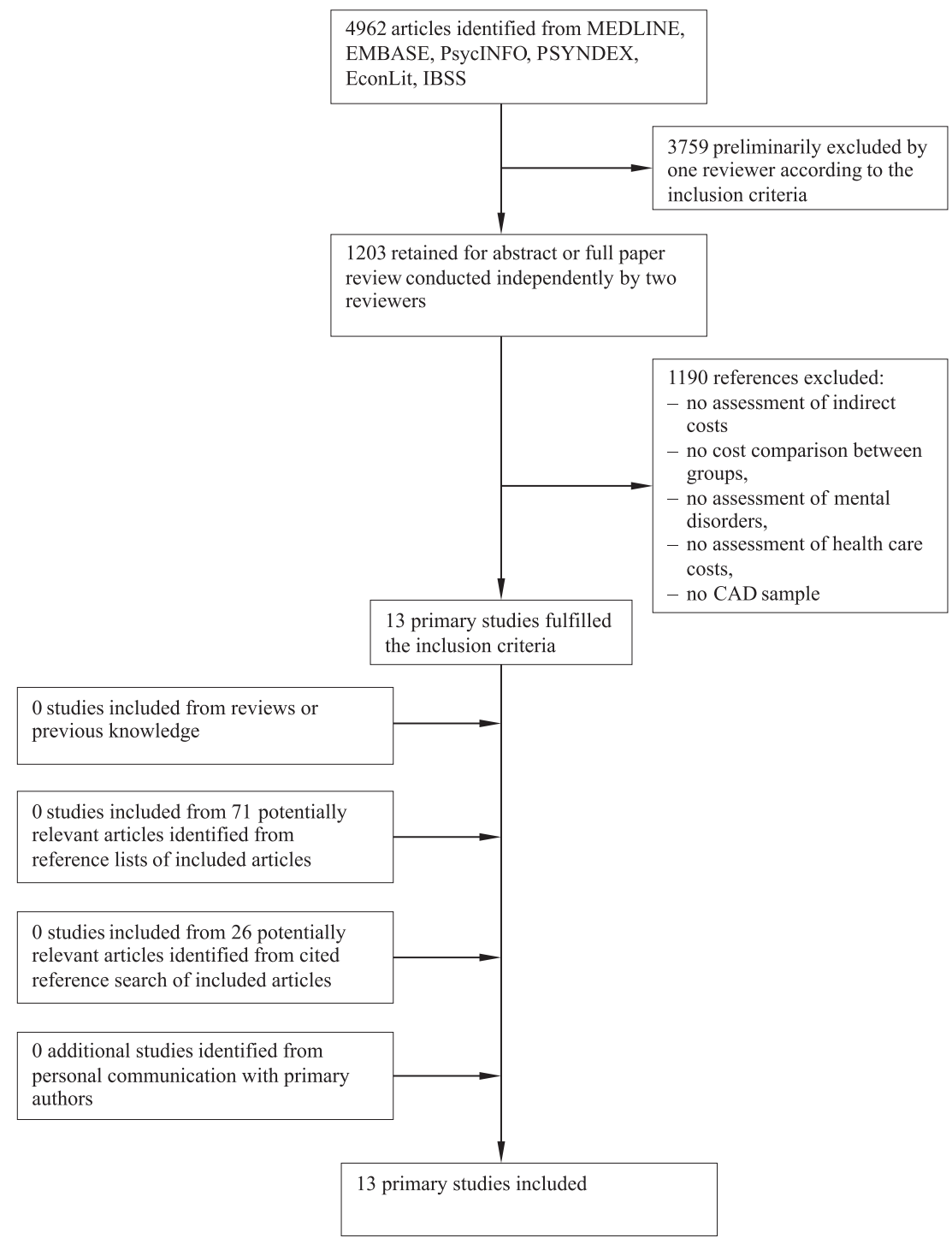

Fig. 1. Selection process of primary studies 
articles citing the included studies (Web of Science Cited Reference Search) $(\mathrm{N}=26)$. In addition, experts in the area were contacted and asked about published or unpublished studies that are relevant to the review.

\section{Data abstraction}

Two reviewers (N.H., A.H.) extracted data, independently of each other, from primary studies using a data extraction form. Information about the participants (sample size, sex and age), type of CAD, mental disorder, assessment method of mental disorders (standardized diagnostic interview, self-report questionnaire, medical record or physician's diagnosis), cut-off scores used to indicate mental disorders on self-report questionnaires, means and standard deviations of mental disorder scores and descriptive statistics of the outcomes were extracted.

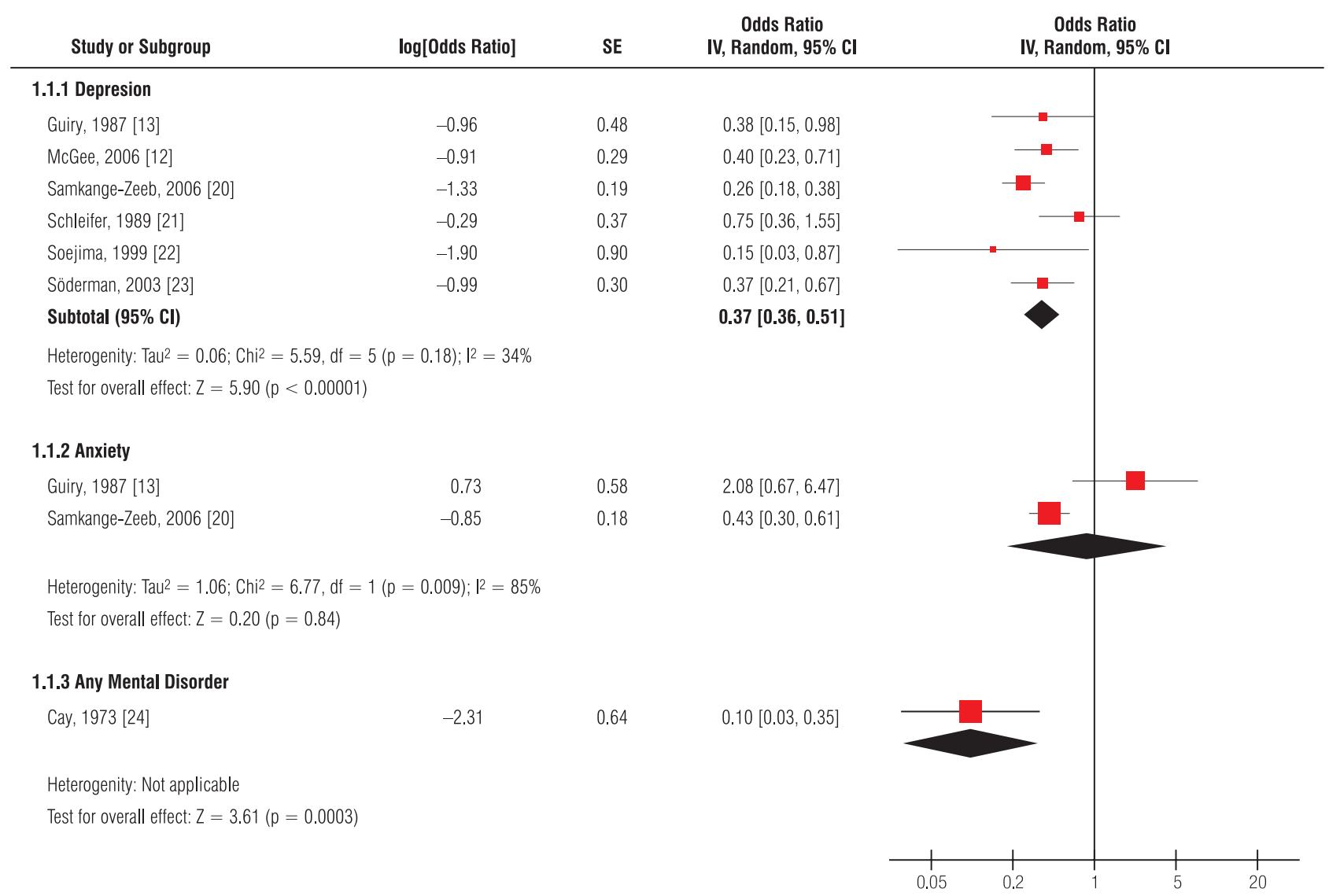

In order to evaluate the methodological characteristics of primary studies, four indicators derived from the Newcastle-Ottawa Scale [18] for assessing the quality of nonrandomized studies were considered. First, the ascertainment of index disease was evaluated to check whether a secure record, self-report with a validated assessment measure or a physician's diagnosis were present. In the cases where no description was given or the CAD diagnosis was based on the patient's self-report without a validated assessment measure, the assessment was rated as insufficient. Next, the ascertainment of mental disorders was rated as methodologically adequate when the assessment was completed by a structured interview, by a self-report with a validated assessment measure or by physician's diagnosis. Furthermore, controlling for age and/or sex and for any additional factor was rated as methodologically sound with regard to

Fig. 2. Primary studies regarding return to work of patients sorted according to mental disorder under study 
the comparability of the groups. Finally, the assessment of indirect health care costs was considered adequate if the studies used database records or the patient's self-report. If no description was given, the assessment was rated as insufficient.

\section{Quantitative data analysis}

The data analysis was completed using Stata Statistical Software 9.0 (StataCorp, College Station, Texas, the USA) and Review Manager 5.0 (Nordic Cochrane Centre, Copenhagen, Denmark). Odds ratios (OR) (95\% CI) were computed to compare return to work rates between the two groups ("comorbid mental disorder" yes/no; "return to work" yes/no).

A forest plot is reported (Figure 2) for all the outcomes examined in five or more primary studies. Studies comparing mentally comorbid patients to patients without mental disorders using beta-coefficients derived from regression analyses were not included in the analysis, due to their methodological shortcomings when used as measures of effect [19].

Heterogeneity was tested for statistical significance by using Q-statistics with 95\% CI. To examine the extent of heterogeneity, $\mathrm{I}^{2}$ was computed [25]. $\mathrm{I}^{2}$ represents the percentage of variability in effect sizes of the primary studies in a metaanalysis that is due to heterogeneity and not chance. We aimed to conduct random-effects meta-analyses indirect cost outcomes with moderate heterogeneity according to the Cochrane Handbook for Systematic Reviews of Interventions ( $\mathrm{I}^{2}$ not important to moderate $\left.(0-60 \%)\right)$ [25].

\section{RESULTS}

The search in electronic databases resulted in 4962 hits. Following the inspection of the titles and abstracts conducted by one reviewer, 1203 of these studies were retained for an evaluation of abstracts or full papers by two reviewers who worked independently of each other. 13 of these studies met the inclusion criteria (Table 1) $[12,13,20-24,26,31]$.

According to the Newcastle-Ottawa Scale, all the studies that fulfilled the ascertainment of index disease with either the data from medical records, a physician's diagnosis or self-report and ascertainment of mental disorder (either in the form of a structured psychiatric interview or validated screening questionnaire). The comparability of the groups (study controls for age and/or sex, study controls for any additional factor) was fulfilled in seven studies [12,20,22,23,26,27,29]. Indirect health care costs were exclusively assessed by a patient's self-report $(\mathrm{N}=13)$ [12,13,20-24,26,31].

The majority of the studies analyzed depressive disorders $(\mathrm{N}=10)$ [12,13,20-23,26,27,30,31], followed by anxiety disorders $(\mathrm{N}=3)[13,20,30]$. Three studies investigated any mental disorder not further specified [24,28,29]. Comorbid mental disorders were assessed by clinical interviews $(\mathrm{N}=3)[13,21,28]$ and screening questionnaires $(\mathrm{N}=9)$ [12,20,22,23,24,26,29-31]. Ladwig et al. (1994) [27] did not describe the assessment of comorbid mental disorders.

\section{Indirect health care costs}

Indirect health care costs were assessed in all 13 studies in terms of return to work [12,13,20-24,26,31]. Seven of these 13 studies reported sufficient data to compute SMDs ranging from 0.10 to 2.08 (Figure 2) [12,13,20-24]. The mean time of a follow-up of the primary studies was 14 months ( $\mathrm{SD}=17.6)$.

The results of the meta-analysis for depression were $\mathrm{OR}=0.37$ (95\% CI: 0.26-0.51) $(\mathrm{N}=6)$. Heterogeneity was low $\left(\mathrm{I}^{2}=34 \%\right)$ (Figure 2) $[12,13,20-23]$. Cay et al. (1973) [24] found diminished return to work in patients with $\mathrm{CAD}$ and any comorbid mental disorder (OR $=0.10$; 95\% CI: 0.03-0.35).

The findings for comorbid anxiety were inconsistent. Guiry (1987) who in his study described both the values 


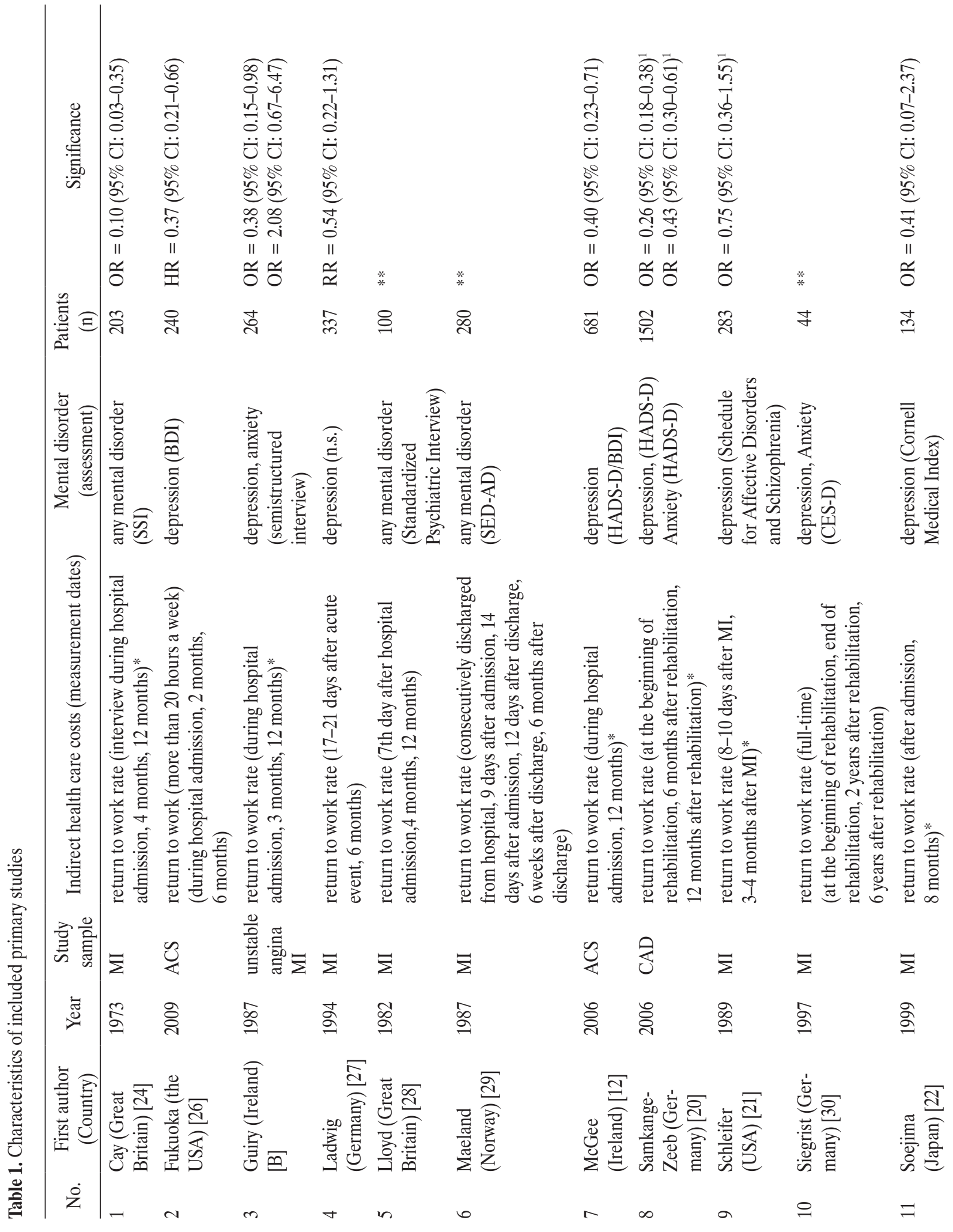




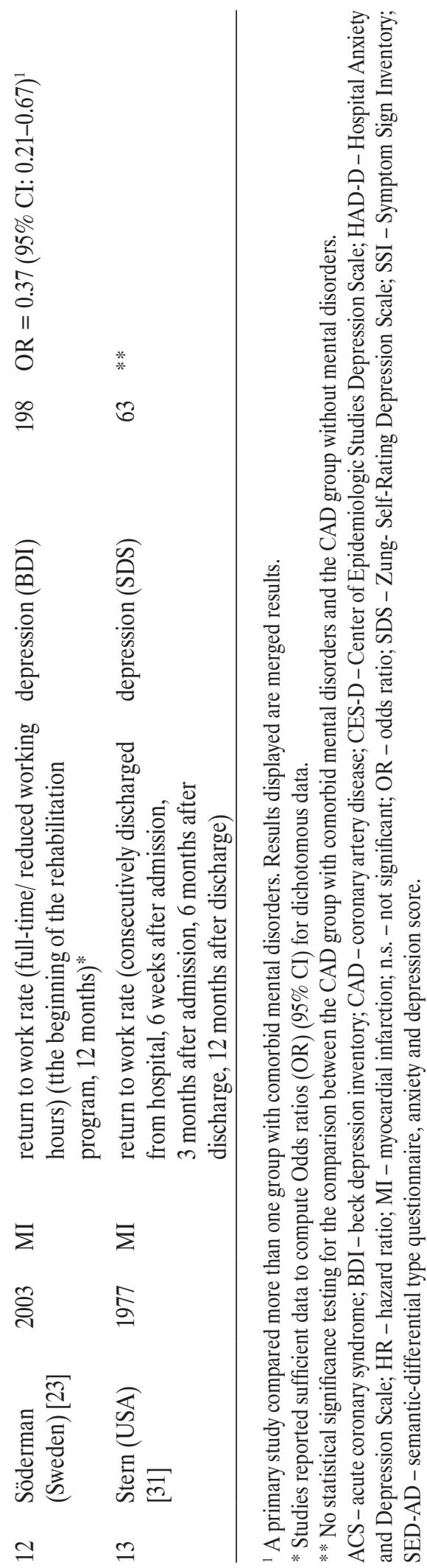

for comorbid anxiety and depression [13] found increased return to work in patients with $\mathrm{CAD}$ and comorbid anxiety $(\mathrm{OR}=2.08$; 95\% CI: 0.67- 6.47), whereas SamkangeZeeb (2006) [20] reported significantly decreased return to work in patients with $\mathrm{CAD}$ and comorbid anxiety $(\mathrm{OR}=0.43 ; 95 \%$ CI: $0.30-0.61)$. Due to a low number of primary studies and high heterogeneity $\left(\mathrm{I}^{2}=85 \%\right)$ the meta-analysis was not computed.

\section{DISCUSSION}

The present review comprehensively summarizes the impact of comorbid mental disorders on indirect health care costs in CAD patients. We found significant increased long-term costs due to diminished return to work in $\mathrm{CAD}$ patients with comorbid depression. This finding is in line with a recent study showing that only $38 \%$ of patients with mild depression or anxiety resumed work three months after the beginning of their sick leave [32]. In contrast, $80 \%$ of all cardiovascular patients without comorbid mental disorders assess themselves as fully capable of taking up work [33]. Furthermore, depressive symptoms were found to be strong predictors of return to work in the studies on patients with myocardial infarction [11]. Against the background of the very high expenditures in CAD patients in general [1,2,34], even small increases of indirect health care costs are highly meaningful for health care professionals and policy makers. In order to assure early return to work and improve work capacity of cardiovascular patients with depression, diagnostics and early treatment of depression need to be an integrative part of CAD health care.

In contrast, the evidence for return to work in CAD patients with comorbid anxiety is inconsistent. This may be due to different study designs of the included primary studies [20,35]. Guiry (1987) [13] interviewed patients after first myocardial infarction during their hospital admission and two follow-ups ( 3 and 12 months), whereas 
Samkange-Zeeb et al. (2006) [20] used a self-report instrument (HADS) to assess a heterogeneous group of CAD patients after PTCA, CABG, myocardial infarctions and other coronary heart problems at the beginning of their rehabilitation as well as 6 and 12 months afterwards. Furthermore, there is a gap of nineteen years of medical progress and change of the health care system and labor market between these two studies. This additionally could have caused inconsistent findings.

There was only one study investigating any mental disorders not further specified, which allowed calculating SMD [24]. Dated in 1973, however, this study is not comparable to other studies due to changes in the health care system, progress of medical equipment and interventions and change of the labor market. Thus, there is no evidence on the association between comorbid mental disorders other than depression and indirect costs in $\mathrm{CAD}$ patients. All 13 primary studies investigated return to work as an indirect cost parameter. At least two methodological aspects need to be taken into account when interpreting the return to work results. First, the term "return to work" might cover both fulltime work resumption and reduced working hours. This may have distorted findings. Only Söderman (2003) [23] differentiated return to work in terms of returning to full-time work or reduced working hours. $33 \%$ of patients with comorbid depression returned to full-time work, whereas only $17 \%$ returned to reduced working hours. In the group of patients without comorbid depression, $55 \%$ returned to full-time work, whereas $28 \%$ reduced their working time. Thus, comorbid depression did not change the ratio of $\mathrm{CAD}$ patients returning to fulltime work or to reduced working hours.

Secondly, Wasiak et al. (2007) [36] conceptualized return to work as a multi-phase process influenced by both individuals and the environment. Therefore, studies investigating this subject should choose an adequate period of time to evaluate the patients' return to work behavior. The primary studies under the present review used a time frame of 14 months at average to assess return to work. This time frame seems appropriate to examine a clinically meaningful delay of return to work. However, to determine whether CAD patients with comorbid mental disorders show a diminished return to work rate, longtime follow-ups until patients' retirement age would be necessary.

We did not find any study that assessed other indirect cost parameters like diminished productivity. Neither was presenteeism investigated in any of the primary studies. Presenteeism is defined as lost productivity while working ill [37]. Kivimäki et al. (2005) [38] investigated sickness presenteeism in employees with previous myocardial infarction and found a Hazard Ratio of 1.97 for the incidence of serious coronary events. This led to the conclusion that patients returning to work too early in their recovery process cause indirect costs due to both loss of productivity and sick leave at a later date due to further coronary events.

Another factor that could have biased the findings is the insufficient differentiation of an occupational group of employees. Several studies found a relationship between return to work and an occupational group, with blue-collar workers showing a higher risk of becoming unable to work compared to white-collar workers $[33,39,40]$. None of the included primary studies, however, differentiated between the patients' occupational groups.

Finally, the included patients stemmed from various workplaces. Different work conditions may mediate the decision to return to work. Earle et al. (2006) [41] showed that patients return to work more frequently if any paid leave $(\mathrm{OR}=2.75)$ or any support from co-workers or supervisor $(\mathrm{OR}=2.42)$ is available. Availability of a flexible work schedule, working fewer hours or changing work tasks showed no differences in return to work [41]. Thus, the effects of comorbid mental disorders on indirect health care costs in CAD patients could also be moderated by workplace conditions. 
To explore the clinical heterogeneity between the primary studies, we aimed to conduct subgroup analyses and metaregressions. The type of comorbid mental disorder, $\mathrm{CAD}$ subtype, study allocation and methodological criteria were defined a priori as potentially relevant effect-modifying variables. However, due to the small number of primary studies, statistical procedures such as subgroup analyses and meta-regressions did not seem to be meaningful.

The studies differed with regard to their time of the baseline assessment. Samkange-Zeeb (2006) [20], Söderman (2003) [23] and Siegrist (1997) [30] assessed patients at the beginning of a rehabilitation program, whereas all other primary studies set their baseline questionnaire at index hospital stay of patients. Therefore, patients in different states of their recovery process were compared, which might have introduced heterogeneity.

Furthermore, most primary studies assessed indirect health care utilization based on patient's self-report. Reliability analyses of retrospective, patient-reported health care costs compared to the cost data from administrative databases and prospective patient's diaries showed moderate to high reliability $[42,43]$. Thus, in general, self-reported health care utilization can be regarded as an adequate assessment strategy in the absence of medical record data. A recent study, however, highlighted that depressed patients tend to misclassify their disease status [44]. If this also applies to self-reported indirect health care utilization data, comparisons between patients with and without comorbid depression regarding indirect health care costs based on a patient's self-report would be biased.

Finally, the assessment of comorbid mental disorders was mainly based on screening instruments. When assessed by screening questionnaires, the group of patients with comorbid mental disorders could comprise patients with clinical disorders as well as patients with subthreshold syndromes. This association is ambiguous, and further studies are therefore needed to clarify the impact of different severity grades of mental disorders on indirect health care costs in CAD patients.

While interpreting the results of this systematic review, some limitations should be considered. First, feasibility considerations led us to restrict our focus to English- and German-language studies. Second, the database search yielded 4962 potentially relevant articles, which were preliminarily evaluated by only one reviewer. 1203 hits were then examined independently by two reviewers. Third, publication bias may have occurred and it remains unclear to what extent insignificant study results were not published. However, with our comprehensive search strategy identifying 13 primary studies, we believe that the present review constitutes a comprehensive and representative view on the topic.

\section{CONCLUSION}

The results of this systematic review indicate a meaningful impact of depression on return to work in CAD patients. Similarly to other diseases $[14,15]$, depression in CAD patients is associated with significant long-term costs caused by diminished return to work, thus generating a profound economic burden for the health care system. Yet, the database is too small and ambiguous to draw conclusions regarding the impact of other mental disorders on indirect cost domains.

\section{REFERENCES}

1. Turpie AG. Burden of disease: medical and economic impact of acute coronary syndromes. Am J Manag Care 2006;12 (16 Suppl):430-4.

2. Leal J, Luengo-Fernandez R, Gray A., Petersen S, Rayner M. Economic burden of cardiovascular diseases in the enlarged European Union. Eur Heart J 2006;27:1610-9. DOI: 10.1093/ eurheartj/ehi733. 
3. Liljas B. How to calculate indirect costs in economic evaluations. Pharmacoeconomics 1998;13(1, Pt 1):1-7.

4. Woo J, Cockram C. Cost estimates for chronic diseases. Dis Manage Health Outcome 2000;8(1):29-41.

5. Ormel J, Korff M von, Burger H, Scott K, Demyttenaere K, Huang YQ, et al. Mental disorders among persons with heart disease - results from World Mental Health surveys. Gen Hosp Psychiatry 2007;29:325-34. DOI:10.1016/j.genhosppsych.2007.03.009

6. Barth J, Schumacher M, Herrmann-Lingen C. Depression as a risk factor for mortality in patients with coronary heart disease: A meta-analysis. Psychosom Med 2004;66:802-13. DOI: 10.1097/01.psy.0000146332.53619.b2.

7. Baumeister H, Hutter N, Bengel J, Härter M. Quality of life in medically ill persons with comorbid mental disorders: A systematic review and meta-analysis. Psychother Psychosom 2011;80:275-86. DOI: 10.1159/000323404.

8. Baumeister H, Balke K, Härter M. Psychiatric and somatic comorbidities are negatively associated with quality of life in physically ill patients. J Clin Epidemiol 2005;58(11):1090-100.

9. Baumeister H, Härter M. Implication of comorbid mental disorders in chronic somatic diseases. Z Med Psychol 2005;14:175-89 [in German].

10. O'Neil A, Sanderson K, Oldenburg B. Depression as a predictor of work resumption following myocardial infarction (MI): a review of recent research evidence. Health Qual Life Outcomes 2010;8(1):95. DOI:10.1186/1477-7525-8-95.

11. Crisp R. Key Factors related to vocational outcome: trends for six disability groups. J Rehabil 2005;71(4):30-7.

12. McGee H, Doyle F, Conroy R, De la Harpe D, Shelley E. Impact of briefly-assessed depression on secondary prevention outcomes after acute coronary syndrome: a one-year longitudinal survey. BMC Health Serv Res 2006;6(1):9. DOI: 10.1186/1472-6963-6-9.

13. Guiry E, Conroy RM, Hickey N, Mulcahy R. Psychological response to an acute coronary event and its effect on subsequent rehabilitation and lifestyle change. Clin Cardiol 1987;10(4):256-60.
14. Hutter N, Knecht A, Baumeister H. Health care costs in persons with asthma and comorbid mental disorders - A systematic review. Gen Hosp Psychiatry 2011;33:443-53.

15. Hutter N, Schnurr A, Baumeister H. Healthcare costs in patient with diabetes mellitus and comorbid mental disorders - A systematic review. Diabetologia 2010;53:2470-9. DOI: $10.1007 / \mathrm{s} 00125-010-1873-\mathrm{y}$

16. Hülsemann JL, Ruof J, Zeidler H, Mittendorf T. Costs in rheumatology: results and lessons learned from the "Hannover Costing Study". Rheumatol Int 2006;26:704-11. DOI: 10.1007/s00296-005-0070-7.

17. Mittendorf T, Merkesdal S, Huelsemann JL, von der Schulenburg JM, Zeidler H, Ruof J. Implementing standardized cost categories within economic evaluations in musculoskeletal diseases. Eur J Health Econ 2003;4(43):43-9. DOI: 10.1007/s10198-002-0149-y.

18. Wells G, Shea B, O'Connell D, Peterson J, Welch V, Losos M, et al. The Newcastle-Ottawa Scale (NOS) for Assessing the Quality of Nonrandomized Studies in Meta-Analysis; 2007 [cited 2012 April 4]. Available from URL http://www.ohri. ca/programs/clinical_epidemiology/oxford.htm.

19. Greenland S, Schlesselman JJ, Criqui MH. The fallacy of employing standardized regression coefficients and correlations as measures of effect. Am J Epidemiol 1986;123(2):203-8.

20. Samkange-Zeeb F, Altenhöner T, Berg G, Schott T.. Predicting non-return to work in patients attending cardiac rehabilitation. Int J Rehab Res 2006;29(1):43-9.

21. Schleifer SJ, Macari-Hinson MM.. The nature and course of depression following myocardial infarction. Arch Intern Med 1989;149(8):1785-9.

22. Soejima Y, Steptoe A, Nozoe S, Tei C. Psychosocial and clinical factors predicting resumption of work following acute myocardial infarction in Japanese men. Int J Cardiol 1999;72(1): 39-47. DOI: org/10.1016/S0167-5273(99)00157-6

23. Söderman E, Lisspers J, Sundin O. Depression as a predictor of return to work in patients with coronary artery disease. Soc Sci Med 2003;56(1):193-202.

24. Cay EL, Vetter N, Philip A, Dugard P. Return to work after a heart attack. J Psychosom Res 1973;17(3):231-43. 
25. Higgins JP, Green S. Cochrane Handbook for Systematic Reviews of Interventions Version 5.0.2 [updated September 2009]. The Cochrane Collaboration, 2009.

26. Fukuoka Y, Dracup K, Takeshima M, Ishii N, Makaya M, Groah $\mathrm{L}$, et al. Effect of job strain and depressive symptoms upon returning to work after acute coronary syndrome. Soc Sci Med 2009;68(10):1875-81. DOI: org/10.1016/j.socscimed.2009.02.030.

27. Ladwig KH, Röll G, Breithardt G, Budde T, Borggrefe M. Post-infarction depression and incomplete recovery 6 months after acute myocardial infarction. Lancet 1994;343(8888): 20-3. DOI: org/10.1016/S0140-6736(94)90877-X.

28. Lloyd GG, Cawley RH. Psychiatric morbidity after myocardial infarction. Q J Med 1982;(51):33-42.

29. Maeland JG, Havik OE. Psychological predictors for return to work after a myocardial infarction. J Psychosom Res 1987; 31(4): 471-81. DOI: org/10.1016/0022-3999(87)90005-5.

30. Siegrist K, Broer M. Work capacity after first myocardial infarction and rehabilitation. Soz Praventivmed 1997;42(6): 358-66 [in German].

31. Stern MJ, Pascale L, Ackerman A. Life adjustment postmyocardial infarction: determining predictive variables. Arch Intern Med 1977;137(12):1680-5.

32. Brouwers EPM, Terluin B, Tiemens BG, Verhaak PFM. Predicting Return to Work in Employees Sick-Listed Due to Minor Mental Disorders. J Occup Rehabil 2009;19(4):323-32. DOI: 10.1007/s10926-009-9198-8.

33. Martimo K, Varonen H, Husman K, Viikari-Juntura E. Factors associated with self-assessed work ability. Occup Med 2007;57(5):380-2. DOI: 10.1093/occmed/kqm028.

34. Melle JP van, Jonge P de, Spijkerman TA, Tijssen JGP, Ormel J, van Veldhuisen DJ, et al. Prognostic association of depression following myocardial infarction with mortality and cardiovascular events: a meta-analysis. Psychosom Med 2004;66(6): 814-22. DOI: 10.1097/01.psy.0000146294.82810.9c.

35. Duric V, McCarson KE. Hippocampal mechanisms linking chronic pain and depression. J Neuropathic Pain Symptom Palliation 2006;2(4):15-32.
36. Wasiak R, Young AE, Roessler RT, McPherson KM, van Poppel MNM, Anema JR. Measuring Return to Work. J Occup Rehabil 2007;17(4):766-81.

37. Cooper C, Dewe P. Well-being-absenteeism, presenteeism, costs and challenges. Occup Med 2008; 58(8):522-4. DOI: $10.1093 /$ occmed/kqn124.

38. Kivimäki M, Head J, Ferrie JE, Hemingway H, Shipley MJ, Vahtera J, et al. Working While Ill as a Risk Factor for Serious Coronary Events: The Whitehall II Study. Am J Public Health 2005;95(1):98-102. DOI: 10.2105/ AJPH.2003.035873.

39. Mark DB, Lam LC, Lee KL, Clapp-Channing NE, Williams RB, Pryor DB, et al. Identification of patients with coronary disease at high risk for loss of employment. A prospective validation study. Circulation 1992;86(5):1485-94. DOI: 10.1161/01.CIR.86.5.1485.

40. Drory Y, Kravetz S, Koren-Morag N, Goldbourtb U. Resumption and Maintenance of Employment after a First Acute Myocardial Infarction: Sociodemographic, Vocational and Medical Predictors. Cardiology 2005;103(1):37-43. DOI: $10.1159 / 000081850$.

41. Earle A, Ayanian J, Heymann J. Work resumption after newly diagnosed coronary heart disease: findings on the importance of paid leave. J Women Health 2006;4(15):430-41.

42. Ritter PL, Stewart AL, Kaymaz H, Sobeld DS, Blocke DR, Loriga KR. Self-reports of health care utilization compared to provider records. J Clin Epidemiol 2001;54(2):136-41. DOI: org/10.1016/S0895-4356(00)00261-4.

43. Lubeck DP, Hubert HB. Self-report was a viable method for obtaining health care utilization data in communitydwelling seniors. J Clin Epidemiol 2005;58(3):286-90. DOI: org/10.1016/j.jclinepi.2004.06.011.

44. Baumeister H, Kriston L, Bengel J, Härter Ml. High agreement of self-report and physician-diagnosed somatic conditions yields limited bias in examining mental-physical comorbidity. J Clin Epidemiol 2010;63:558-65. DOI: org/10.1016/j.jclinepi.2009.08.009.

This work is available in Open Access model and licensed under a Creative Commons Attribution-NonCommercial 3.0 Poland License - http://creativecommons.org/ licenses/by-nc/3.0/pl/deed.en. 